http://jmscr.igmpublication.org/home/

ISSN (e)-2347-176x ISSN (p) 2455-0450

crossref DOI: https://dx.doi.org/10.18535/jmscr/v9i5.30

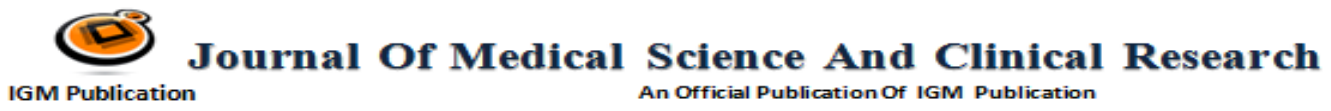

\title{
Fundus camera for all
}

Authors

\section{Dr Silni Chandra ${ }^{1}$, Dr Sandhya Somasundaram ${ }^{2}$, Dr Padma B Prabhu ${ }^{3}$, Dr Ranjini K. ${ }^{4}$, Amal P.G. ${ }^{5}$, Aldrin Thomas ${ }^{6}$, Abhay P.S. ${ }^{7}$, Abhijith M. ${ }^{8}$, Anand Ravi ${ }^{9}$ \\ ${ }^{1,2}$ Assistant Professor, Department of Ophthalmology, Government Medical College, Kozhikode, 673008 \\ ${ }^{3,4}$ Additional Professor, Dept. Of Ophthalmology, Government Medical College, Kozhikode \\ ${ }^{5,6}$ House Surgeon, Government Medical College, Kozhikode, 673008 \\ ${ }^{7,8,9}$ MBBS Student $-7^{\text {th }}$ Semester, Government Medical College, Kozhikode, 673008}

\section{Introduction}

Use of smart phone for imaging the fundus has been a technique which has taken the world by storm. Initially only the expensive iPhones ${ }^{1}$ could be used but since the advent of good quality android phones with high resolution camera, fundus imaging is now literally at everybody's finger tips. These smart phones have been used for indirect ophthalmoscopy, direct ophthalmoscopy and anterior segment imaging For Indirect ophthalmoscopy, only a condensing lens is required apart from the mobile phone. For direct ophthalmoscopy an LED light source is attached to the mobile phone close to the camera ${ }^{2}$.

In the technique described by Nazari et al ${ }^{3}$ the smart phone fundus imaging was done with a condensing lens in one hand and a smart phone in other hand. This was similar to the technique described by Shanmugham et al and Lord et $\mathrm{al}^{1,2}$. In all these techniques high amount of precision and hand coordination was required so it was a challenge for many. To maintain alignment between the smart phone and the condensing lens the need for a structural support was recognized. ${ }^{4}$ These were provided either by PVC pipes, plastic bottles or plastic arm made using 3D printing technology in the later innovations. These were glued to a mobile cover on one side and a condensing lens fixed to the other end..$^{4-6}$

This article is about a fundus camera built indigenously by the students and house surgeons posted in department of Ophthalmology of Government Medical College, Kozhikode, Kerala. The traditional hand held fundus camera which have been described innumerable times in various journals and during conferences was modified to suit the multifarious requirements in a teaching hospital. ${ }^{3-5}$ This camera could be made and used by ophthalmologists, post graduate students, house surgeons and even undergraduate students with some amount of training.

\section{Methods}

The fundus camera was made using PVC pipe, PVC stopper and a selfie stick/ mobile stand. This selfie stick/ mobile stand was used keeping in mind the different sizes and shapes of smart phones which are available in the market, since this fundus camera would be used by multiple people and a fixed size of the phone cover as used 
in other models would have been a hinderance to its main purpose of being multiple user friendly. Apart from this since it was an attempt to be useful for all a rubber bush was attached to the opposite end of the PVC pipe which can be rested on the patient's orbit. This will help in keeping the hands steady and will be useful for those who are not very familiar with the technique of indirect ophthalmoscopy like the house surgeons and the undergraduate students.

\section{Steps}

Step 1- Take a PVC pipe $15 \mathrm{~cm}$ long.

Step 2- Attach the PVC stopper $5 \mathrm{~cm}$ long to one end of the PVC pipe. See to it that it snugly fits the PVC pipe. Make a circular opening in the stopper which is slightly less than the diameter of the condensing lens (Figure 1,2)

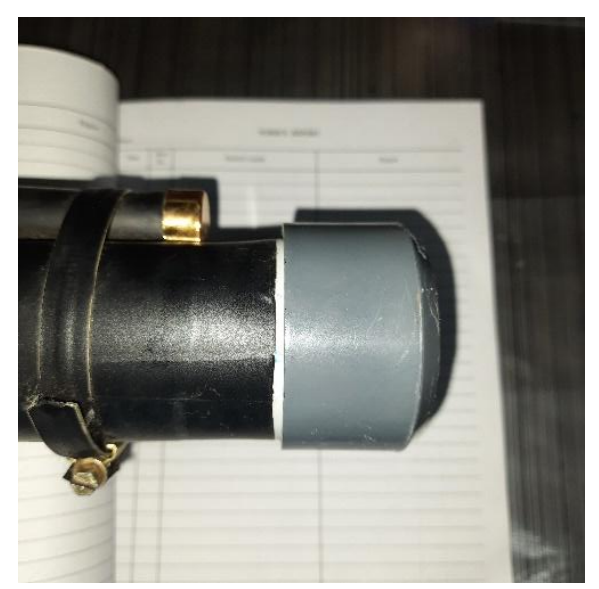

Fig. 1 -PVC pipe with PVC stopper attached to one end

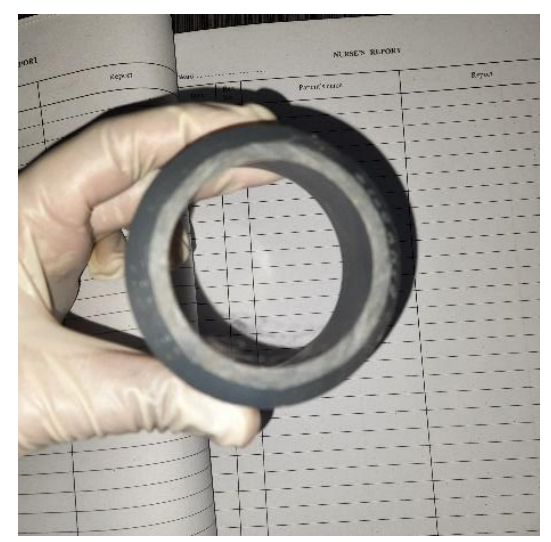

Fig.2- PVC stopper with circular opening
Step 3- Attach a Rubber bush of length 4.5 to 7 $\mathrm{cm}$ to the PVC stopper, this is optional only for those who are not familiar with the technique of indirect ophthalmoscopy. (figure 3)

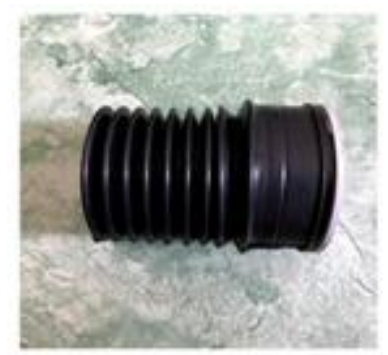

Fig. 3- Rubber bush

Step 4- Cover the inside and the outside of the PVC pipe with insulation tape. To prevent the condensing lens from sliding through the PVC pipe, stick 2 layers of double-sided tape to the end of the PVC pipe on the inside.(Figure 4,5)

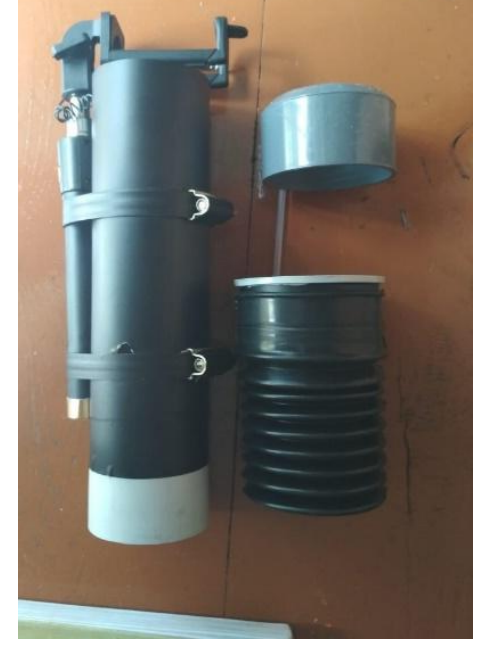

Fig. 4 PVC pipe covered with insulation tape

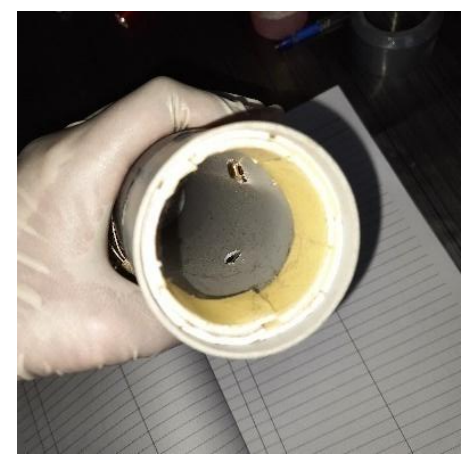

Fig. 5 PVC pipe with 2 layers of double-sided tape

Step 5- To the body of the PVC pipe attach the selfie stick/ mobile stand using clamps in such a 
manner that the mobile holder comes to the opposite end of the PVC pipe. (Figure 6,7)

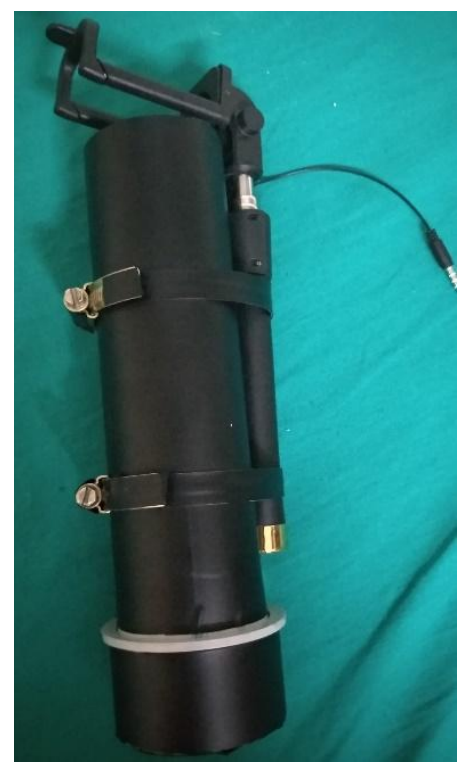

Fig. 6 Fundus camera with the selfie stick

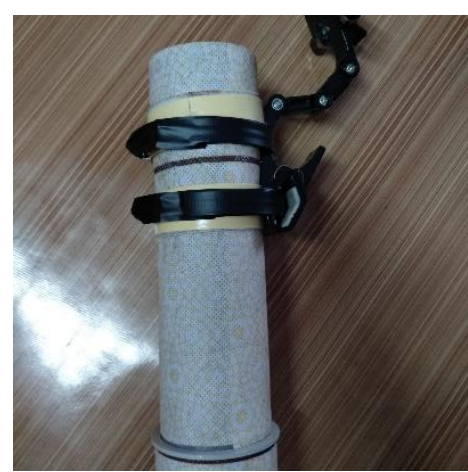

Fig 7 Fundus camera with mobile stand

Fit in a $20 \mathrm{D}$ in the PVC stopper. Fix a smart phone in the mobile holder. Align the camera and the flash so that it comes in the centre of the PVC pipe. The Fundus camera is ready for use.

Keep in the video mode or the photo mode. In either of these options keep the torch/ fill light option ON.

Editing of the photos can be done using the edit options for altering the brightness and the contrast and to reduce the reflections.

With some amount of training, it is easy to master fundus photography with this hand-held fundus camera.

\section{Discussion}

This Fundus camera functions similar to an indirect ophthalmoscope. The flash light from the mobile phone illuminates the fundus and the image formed by the condensing lens is captured by the mobile phone. It has been successfully used to produce good quality reproducible fundus images (Figure 8). It does require some amount of training to get good quality fundus images and the quality improves as one gains experience in using this. ${ }^{7}$ In the earlier generation mobile phones, the flash could not be kept continuously on so still photography was not possible and indirect ophthalmoscopy could be done only in the video mode, but with the advent of the newer generation mobile phones in which the flash can be kept continuously on, this problem too has been solved. Thus, image capturing is now possible in the still photography mode. The presence of a selfie button helps in single handed use of this fundus camera which helps in doing scleral indentation with the other

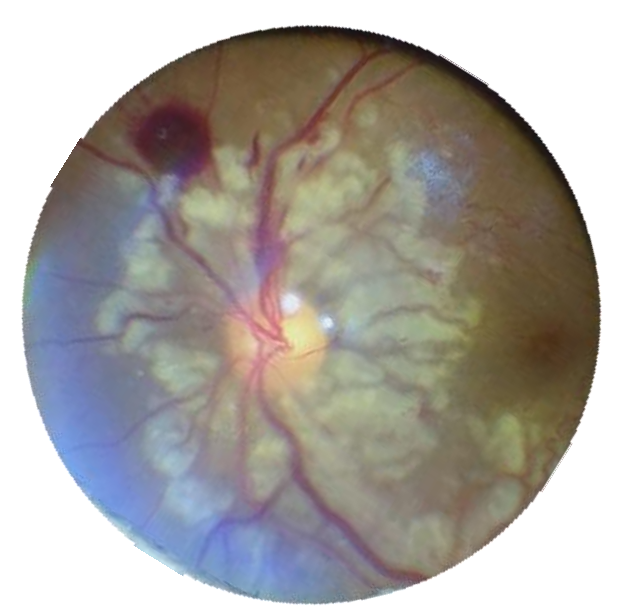

Fig 8 Purtschers retinopathy- taken with the handheld fundus camera

It has been used for the bed side teaching sessions, presentations, patient education in busy OPD's, during emergency duty, for documentation purposes, in bed ridden patients, in inter departmental consultation in multi-speciality hospitals and for screening of patients for diabetic retinopathy and glaucoma in camps. ${ }^{1,2,8}$ This can also be used for ROP screening purposes and also 
for documentation ${ }^{9}$. It can be used in medicolegal cases wherein access to a standard fundus camera is not possible. It will also help in getting immediate opinionin difficult cases which would be of immense help for Ophthalmology post graduates and fellows. It can also be used for training post graduates from other departments who may be interested in fundus viewing. In fact, it can be used for all purposes where presently indirect ophthalmoscopy is being done. In this age of corona virus and Nipah virus, the use of direct ophthalmoscopy, which is still used unrestrainedly in medical colleges, during cross consultation, is fraught with risk since it requires close contact with the patient. In such a situation the use of this fundus camera will minimize the risk.

Apart from fundus imaging this camera can also be used for taking anterior segment photographs and video imaging purposes.

Presently, the talk is about artificial intelligence in the diagnosis of diabetic retinopathy but with the use of this humble hand-held fundus camera even technicians, nursing students, undergraduate MBBS students (Figure 6) can be utilized fruitfully in screening of diabetic retinopathy in camps. And once fully trained the MBBS doctors themselves will be able to diagnose and refer patients without delay. This may go a long way in reducing the burden of blindness due to diabetic retinopathy. ${ }^{8}$ Even early diagnosis of Primary open angle glaucoma will be possible which will in turn help in reducing blindness due to glaucoma.

These types of hand-held fundus camera may revolutionize the way MBBS teaching in Ophthalmology is carried out.

\section{References}

1. Lord RK, Shah VA, Filippo ANS, Krishna R. Novel Uses of Smartphones in Ophthalmology. Ophthalmology [Internet]. 2010 Jun 1 [cited 2020 May 17];117(6):1274-1274.e3. Available from: https://www.aaojournal.org/article/S01616420(10)00002-3/abstract
2. Shanmugam M, Mishra D, Madhukumar R, Ramanjulu R, Reddy S, Rodrigues G. Fundus imaging with a mobile phone: A review of techniques. Indian J Ophthalmol. 2014 Sep 1;62:960-2.

3. Nazari Khanamiri H, Nakatsuka A, ElAnnan J. Smartphone Fundus Photography. J Vis Exp JoVE [Internet]. 2017 Jul 6 [cited 2020 May 5];(125). Available from: https://www.ncbi.nlm.nih.gov/pmc/articles /PMC5609317/

4. Chandrakanth $P$, Ravichandran R, Nischal NG, Subhashini M. Trash to treasure Retcam. Indian J Ophthalmol [Internet]. 2019 Apr [cited 2020 May 5];67(4):541-4. Available from: https://www.ncbi.nlm.nih.gov/pmc/articles /PMC6446627/

5. Raju B, Raju NSD, Akkara JD, Pathengay A. Do it yourself smartphone fundus camera - DIYretCAM. Indian J Ophthalmol [Internet]. 2016 Sep 1 [cited 2020 May 5];64(9):663. Available from: http://www.ijo.in/article.asp?issn=03014738; year $=2016$; volume $=64$;issue $=9$; spage $=663 ;$ epage $=667 ;$ aulast $=$ Raju $;$ type $=0$

6. 3D Printed Smartphone Indirect Lens Adapter for Rapid, High Quality Retinal Imaging | Journal of Mobile Technology in Medicine [Internet]. [cited 2020 May 17]. Available from: https://www.journalmtm.com/2014/3dprinted-smartphone-indirect-lens-adapterfor-rapid-high-quality-retinal-imaging/

7. Adam MK, Brady CJ, Flowers AM, Juhn AT, Hsu J, Garg SJ, et al. Quality and Diagnostic Utility of Mydriatic Smartphone Photography: The Smartphone Ophthalmoscopy Reliability Trial. Ophthalmic Surg Lasers Imaging Retina. 2015 Jun;46(6):631-7.

8. Bolster NM, Giardini ME, Bastawrous A. The Diabetic Retinopathy Screening Workflow. J Diabetes Sci Technol 
[Internet]. 2015 Nov 23 [cited 2020 May 17];10(2):318-24. Available from: https://www.ncbi.nlm.nih.gov/pmc/articles /PMC4773975/

9. Raju B, Raju NSD, Akkara JD, Pathengay A. Smartphone-based fundus documentation in retinopathy of prematurity. Indian J Ophthalmol. 2019;67(11):1909. 